\title{
The Role of Ultrasound versus Hysteroscopy in Assessment of Cesarean Section Scar in Non Pregnant Females
}

\author{
Islam Ibrahim Abdel-Aziz El-Ewiny*, Farid Ahmed Kassab, Kamel Nour el-Dean Abdul-Jaleel \\ Department of Obstetrics and Gynecology, Faculty of Medicine, Al-azhar University, Cairo, Egypt \\ *Corresponding author: Islam Ibrahim Abdel-Aziz El-Ewiny, Email: drislamelewiny@gmail.com
}

\begin{abstract}
Background: cesarean section is one of the most commonly performed surgical procedures in obstetric practice. It has become increasingly important to study the sequelae of this procedure on the future reproductive capacity. Special investigations are required for assessment of CS scar integrity to avoid its dehiscence or rupture during pregnancy or labor.

Objectives: to compare between the accuracy of ultrasound and hysteroscopy in visualization of the site of Cesarean section scar in non-pregnant females and also to determine and comment on thickness, vascularity, continuity and ballooning of the scar.

Patients and Methods: in a comparative cross-sectional study, 50 women with previous cesarean section attending the $\mathrm{Ob} / \mathrm{Gyne}$ outpatient clinic complaining of infertility or recurrent pregnancy loss. They had been examined by transvaginal ultrasound (TVS), then by hysteroscopy to evaluate and compare their accuracy in assessment of the scar.

Results: it was found that hysteroscopy can't comment on scar thickness but transvaginal ultrasound can do it in all patients of the study with a mean value $1.57 \mathrm{~mm}$. There is a statistically significant correlation between the use of ultrasound and hysteroscopy in determination of the site, continuity and vascularity of scar, while there is a statistically insignificant correlation between ultrasound and hysteroscopy in determination of the balloning of the scar.

Conclusion: ultrasound is more accurate than hysteroscopy in evaluating scar thickness and detection of scar defect.

Keywords: Cesarean section scar, ultrasonography, hysteroscopy.
\end{abstract}

\section{Introduction}

Cesarean section (CS) is one of the most commonly performed surgical procedures in obstetric practice, as large number of women are undergoing this vital operation each year, it has become increasingly important to study the sequelae of this procedure on the future reproductive capacity ${ }^{(\mathbf{1})}$.

Cesarean section is associated with complications in subsequent pregnancies, such as placenta previa, placenta accreta, increta or percreta, dehiscence or uterine rupture. Also the surgical maternal morbidity including risk of bowel and bladder injury is significantly increased ${ }^{(2)}$.

Cesarean sections are usually performed by incision of the lower uterine segment. Women with previous Cesarean section may develop intrauterine adhesions with subsequent infertility, recurrent pregnancy loss or menstrual disorders ${ }^{(3)}$. Moreover, women with previous Cesarean section are considered a high risk patient when she gets pregnant and requires special investigations for assessment of scar integrity to avoid its dehiscence or rupture during pregnancy or labor ${ }^{(4)}$.

For women who have had previous Caesarean section, choices for mode of birth in their next pregnancy are either trial of Vaginal Birth after Cesarean (VBAC) or an Elective Repeat Cesarean $(\mathrm{ERC})^{(2)}$.

In the recent years, VBAC was found to be less safe than was thought previously. This fact led to less obstetricians offering and less patients accepting VBAC. Decreased utilization of VBAC and increased rates of ERC is one of the major factors behind global increase in Cesarean section rates ${ }^{(5)}$.

Uterine rupture due to dehiscence of the previous CS scar is one of the most morbid and catastrophic complications that may happen during delivery either by VBAC or ERC. The risk of uterine rupture during VBAC trial is estimated to be $74 / 10000^{(6)}$. 
Fetal risks of VBAC include Hypoxic Ischemic Encephalopathy and stillbirth ${ }^{(7)}$.

Both VBAC and ERC have their own risks and benefits. However, VBAC is proved to be practical and relatively safe mode of delivery. Due to possible complications on both sides, case selection and patient counseling are of utmost importance $^{(8)}$.

Many authors have tried to predict the possibility of scar dehiscence and uterine rupture. Prediction of scar dehiscence is very important in order to avoid these catastrophic complications and will help in patient selection for VBAC. Trails have been made to visualize previous CS scar ${ }^{(9)}$.

Many methods have been suggested, including Hysterography, ultrasonography, sonohysterography, hysteroscopy and magnetic resonance imaging ${ }^{(9)}$.

The role of ultrasound in visualization and detection of CS scar defects in non-pregnant females has been investigated. Two dimensional (2D) transvaginal ultrasound was found to be an accurate method for measurement of scar thickness. Also colored Doppler was found to be useful in detecting the vascularity of the scar ${ }^{(2)}$.

Diagnostic hysteroscopy was considered the "gold standard" for the diagnosis of intrauterine abnormalities; it has been shown to be a sensitive tool for direct visualization of uterine scar and intrauterine adhesions ${ }^{(\mathbf{1 0})}$.

The objective of this study is to compare ultrasonography versus hysteroscopy for the assessment of the cesarean section scar in women with a previous cesarean section.

\section{Patients and methods}

It is a comparative cross-sectional study that was conducted in Maternity hospital, Sayed Galal University Hospital, during the period from Sep. 2017 to Oct. 2018.

The study was done on 50 women with previous cesarean section attending the Ob/Gyne outpatient clinic complaining of infertility or recurrent pregnancy loss. They had been subjected to full history, examined by transvaginal ultrasound (TVS), then by hysteroscopy to evaluate and compare their accuracy in assessment of the scar (site, thickness, vascularity, continuity and ballooning).

Inclusion criteria include non-pregnant females who have previous section since at least 3 months, with no co-existing medical conditions to be controlled. Patients were assessed post menstrually.

Exclusion criteria include pregnant females, women with no previous sections, patient with more than one cesarean section, patients with any focal lesion such as fibroids, adenomyosis, endometrial polyp, or endometrial hyperplasia and patients who have associated pathology in their ovaries.

During the visit, a written consent was obtained from each woman and a detailed explanation to the woman about the technique, its value and its expected complications.

Every patient was subjected to:

(A) History taking and examination: including general examination, abdominal examination to exclude pregnancy \& assess scar (size, site, tenderness) and gynecological examination to exclude pelvic infection, pregnancy and cervical pathology.

(B) Sonographic examination: 2D Ultrasound and Doppler carried out at ultrasound unit to detect the previous uterine scar. It was performed with a GE Voluson E6 ultrasound machine with a 7.5 $\mathrm{MHz}$ transvaginal probe. The ultrasonographic assessment was based on: (1) measurement the thickness of the scar; (2) assessment of the site, vascularity and continuity of the scar; (3) if there is ballooning or not.

\section{(C) Hysteroscopic Evaluation:}

Diagnostic hysteroscopy was carried out to all patients under anashesia by a single experienced operator who was blinded to the ultrasound findings.

Hysteroscopic examination was performed using a rigid $30^{\circ}$ hysteroscope with a $4 \mathrm{~mm}$ diameter diagnostic sheath (Karl Storz Endoscopy, Germany). A high intensity cold light source and fiberoptic cable were used to illuminate the uterine cavity. Normal saline was used to distend the uterine cavity at a maximum pressure of 100 $\mathrm{mmHg}$. 
Detailed assessment of the CS scar and uterine cavity was done systematically. The hysteroscopic assessment was based on: (1) condition of the scar site, thickness, continuity, vasculature, and if healthy (pinkish) or unhealthy (fibrosed) scar; (2) presence of scar defect; and (3) presence of intrauterine adhesions related to the scar; and its type (thin or thick), site and extent.

\section{Ethical considerations:}

Written consents were obtained from all patients before getting them involved in the study. The steps of the study, the aims, the benefits and disadvantages were discussed with patient. Patients were informed about any abnormal results of procedures and tests performed and were instructed and treated accordingly. The patients had the right to refuse participation. Confidentiality of all data and test results of all the study population was preserved. The study was approved by the Ethics Board of Al-Azhar University.

\section{Statistical analysis:}

Collected data were processed using SPSS version 15 (SPSS Inc., Chicago, IL, USA). Quantitative data are expressed as means \pm SD while qualitative data are expressed as numbers and percentages (\%). Student $t$ test and ANOVA test (Analysis of variances) were used to test significance of difference for quantitative variables that follow normal distribution and Chi Square was used to test significance of difference for qualitative variables. A probability value ( $\mathrm{p}$-value) $<0.05$ was considered statistically significant. ROC curve (receiver operator characteristic curve) was constructed for scar thickness.

\section{Results}

Table (1) presents the clinical data of the patients. The study comprised 50 women with previous CS. 41 patients were complaining of infertility while 9 patients were complaining of recurrent pregnancy loss.

Table (1): statistical analysis of demographic data of the study group

\begin{tabular}{|l|l|l|l|l|l|}
\hline & Mean & $\begin{array}{l}\text { Standard } \\
\text { Deviation }\end{array}$ & Median & Minimum & Maximum \\
\hline Age & 32.12 & 6.28 & 31.50 & 21.00 & 35.00 \\
\hline Parity & 1.66 & 0.82 & 1.00 & 1.00 & 3.00 \\
\hline N of yrs from last CS & 3.74 & 2.74 & 3.00 & 0.75 & 12.00 \\
\hline
\end{tabular}

As regard scar thickness, it was found that hysteroscopy can't comment on thickness of scar of previous sections but transvaginal ultrasound can do it in all patients of the study by mean value 1.57 and median 1.50 and standard deviation (table 2).

Table (2): Statistical analysis of thickness of scar obtained by ultrasound

\begin{tabular}{|l|l|l|l|l|l|}
\hline & Mean & $\begin{array}{l}\text { Standard } \\
\text { Deviation }\end{array}$ & Median & Minimum & Maximum \\
\hline Scar thickness $(\mathrm{cm})$ & 1.57 & 0.71 & 1.50 & 0.50 & 3.10 \\
\hline
\end{tabular}

As regard the site of the scar of previous sections, there is a statistically significant correlation between the use of ultrasound and hysteroscopy in determination of the site of scar of previous Cesarean sections with (P-value: 0.001 ) as shown in tables $3,4 \& 5$.

Table (3): Agreement between US and hysteroscopy as regard site of scar

\begin{tabular}{|l|l|l|l|}
\hline & & Count & $\%$ \\
\hline \multirow{2}{*}{ Site (US) } & Above. int. os & 14 & $28.0 \%$ \\
\cline { 2 - 4 } & Below int. os & 36 & $72.0 \%$ \\
\hline \multirow{2}{*}{ Site (HYSTEROSCOPY) } & Above int. os & 13 & $26.0 \%$ \\
\cline { 2 - 4 } & Below int. os & 37 & $74.0 \%$ \\
\hline
\end{tabular}


The Role of Ultrasound versus Hysteroscopy in Assessment of Cesarean...

Table (4): Correlation between US and hysteroscopy as regard site

\begin{tabular}{|l|l|l|l|l|l|}
\hline & & \multicolumn{3}{|l|}{ site (US) } & \multicolumn{3}{|l|}{ Below int. os } \\
\hline & & Above. int. os & Count & $\%$ \\
\hline & & Count & $\%$ & 0 & $.0 \%$ \\
\hline \multirow{2}{*}{ site (hysteroscopy) } & Above. int. os & 13 & $92.9 \%$ & 36 & $100.0 \%$ \\
\cline { 2 - 6 } & Below int. os & 1 & $7.1 \%$ & 36 \\
\hline
\end{tabular}

Table (5): Correlation between us and hysteroscopy as regard site

\begin{tabular}{|c|c|c|}
\hline & Value & P value \\
\hline Measure of Agreement Kappa & $\mathbf{0 . 9 4 9}$ & $<\mathbf{0 . 0 0 1}$ \\
\hline
\end{tabular}

As regard ballooning of the scar, there is a statistically insignificant correlation between the use of ultrasound and hysteroscopy in determination of the balloning of scar of previous Cesarean sections with (Pvalue: $\mathbf{0 . 6 2 1}$ ) as shown in tables $6,7 \& 8$.

Table (6): Agreement between US and hysteroscopy as regard ballooning

\begin{tabular}{|l|l|l|l|}
\hline & & Count & $\%$ \\
\hline \multirow{2}{*}{ balloning (US) } & yes & 6 & $12.0 \%$ \\
\cline { 2 - 4 } & no & 44 & $88.0 \%$ \\
\hline \multirow{2}{*}{ balloning (Hysteroscopy) } & yes & 12 & $24.0 \%$ \\
\cline { 2 - 4 } & no & 38 & $76.0 \%$ \\
\hline
\end{tabular}

Table (7): Correlation between US and hysteroscopy as regard ballooning

\begin{tabular}{|c|c|c|c|c|c|}
\hline & & \multicolumn{4}{|c|}{ balloning (US) } \\
\hline & & \multicolumn{2}{|c|}{ yes } & \multicolumn{2}{|l|}{ No } \\
\hline & & Count & $\%$ & Count & $\%$ \\
\hline \multirow{2}{*}{$\begin{array}{l}\text { balloning } \\
\text { (Hysteroscopy) }\end{array}$} & Yes & 2 & $33.3 \%$ & 10 & $22.7 \%$ \\
\hline & No & 4 & $66.7 \%$ & 34 & $77.3 \%$ \\
\hline
\end{tabular}

Table (8): Correlation between us and hysteroscopy as regard ballooning with $P$ value $=0.621$.

\begin{tabular}{|c|c|c|}
\hline & Value & P value \\
\hline Measure of Agreement & $\mathbf{0 . 0 7 4}$ & $\mathbf{0 . 6 2 1}$ \\
Kappa & & \\
\hline
\end{tabular}

As regatrd continuity of the scar of previous sections, there is a statistically significant correlation between the use of ultrasound and hysteroscopy in determination of the continuity of scar of previous Cesarean sections with (P-value: 0.001) as shown in tables $9,10 \& 11$.

Table (9): Agreement between us and hysteroscopy as regard continuity

\begin{tabular}{|l|l|l|l|}
\hline \multicolumn{2}{|c|}{} & Count & $\%$ \\
\hline \multirow{2}{*}{ continuity (US) } & yes & 40 & $80.0 \%$ \\
\cline { 2 - 4 } & no & 10 & $20.0 \%$ \\
\hline \multirow{2}{*}{$\begin{array}{l}\text { continuity } \\
\text { (Hysteroscopy) }\end{array}$} & yes & 38 & $76.0 \%$ \\
\cline { 2 - 4 } & no & 12 & $24.0 \%$ \\
\hline
\end{tabular}

Table (10): Correlation between us and hysteroscopy as regard continuity

\begin{tabular}{|l|l|l|l|l|l|}
\hline \multicolumn{2}{|c|}{} & \multicolumn{4}{|l|}{ Continuity (US) } \\
\cline { 3 - 6 } \multicolumn{2}{|c|}{} & Yes & No & Count & $\%$ \\
\cline { 3 - 6 } \multicolumn{2}{|c|}{} & Count & $\%$ & 3 & $30.0 \%$ \\
\hline $\begin{array}{l}\text { Continuity } \\
\text { (hysteroscopy) }\end{array}$ & Yes & 35 & $87.5 \%$ & 7 & $70.0 \%$ \\
\cline { 2 - 6 } & No & 5 & $12.5 \%$ & 7 & 3 \\
\hline
\end{tabular}


Islam El-Ewiny et al.

Table (11): correlation between us and hysteroscopy as regard continuity with $P$ value $=0.001$

\begin{tabular}{|c|c|c|}
\hline & Value & P value \\
\hline Measure of Agreement & $\mathbf{0 . 5 3 5}$ & $\mathbf{0 . 0 0 1}$ \\
Kappa & & \\
\hline
\end{tabular}

As regard vascularity of the scar of previous sections, there is a statistically significant correlation between the use of ultrasound and hysteroscopy in determination of the vascularity of scar of previous Cesarean sections with (P-value: 0.001 ) as shown in table $12 \& 13$.

Table (12): Agreement between us and hysteroscopy as regard vascularity of the scar

\begin{tabular}{|c|c|c|c|}
\hline & & Count & $\%$ \\
\hline \multirow[t]{2}{*}{ vascularity (US) } & Yes & 26 & $52.0 \%$ \\
\hline & No & 24 & $48.0 \%$ \\
\hline \multirow[t]{2}{*}{ vascularity (Hysteroscopy) } & Yes & 24 & $48.0 \%$ \\
\hline & No & 26 & $52.0 \%$ \\
\hline
\end{tabular}

Table (13): correlation between us and hysteroscopy as regard vascularity of the scar with $P$ value $<0.001$.

\begin{tabular}{|l|l|l|}
\hline & \multicolumn{1}{|c|}{ Value } & \multicolumn{1}{c|}{ P value } \\
\hline $\begin{array}{l}\text { Measure of Agreement } \\
\text { Kappa }\end{array}$ & 0.650 & $<0.001$ \\
\hline
\end{tabular}

\section{Discussion}

In past decades the Cesarean section rate has increased markedly ${ }^{(11,12)}$.

Cesarean sections are usually performed by incision of the lower uterine segment. Sonographic studies have revealed various changes in the anterior uterine wall following the operation ${ }^{(13,14,15)}$.

The present work aimed to compare between the accuracy of ultrasound (2D \& Doppler) and hysteroscopy in determine the myometrium thickness at the level of the isthmus uteri and location of scar defect in women with previous cesarean section

Results of this study reported that the Ultrasound (2D\&Doppler) is more accurate than hysteroscopy in the description of the scar of previous section (site, thickness, vascularity, continuity and ballooning) in order to help obstetricians to choose the mode of delivery and prevent the complications that may occur in females with previous section.

Results of present study are in agreement with finding reported by $\boldsymbol{O}$ sser $\boldsymbol{e t} \boldsymbol{a l}$. ${ }^{(16)}$; there was significant decrease of the myometrial thickness in the isthmus uteri in patients with previous cesarean section.
In the present study only 10 patients out of 50 have scar defect (20\%). However, Armstrong et al. ${ }^{(17)}$ detected scar defects in $43 \%$ of their patients. Others found scar defects in $42 \%^{(18)}, 19 \%^{(19)}$, and $69 \%^{(16)}$ of their patients.

Results of Hanfy and Abdel Malek (20), suggested that the use of 3D ultrasound may decrease the interobserver variability of results as compared to 2D ultrasound.

It is evident that all previous studies on this issue have demonstrated a significant relation between scar thickness as measured by ultrasound (regardless of the timing and route of sonography) and operative scar thickness.

However, the cut-off value for determining safe vaginal delivery is still a great point of controversy. Several authors have performed many trials and reproduced many values but none was satisfactory and no universal cut off point could be reached at the moment. Different studies had different results and the cut-off point varied from as low as $1.5 \mathrm{~mm}$ to as high as $4 \mathrm{~mm}$. And again, this is attributable to different techniques of sonographic measurement of scar thickness and myometrial thickness ${ }^{(21)}$.

The clinical importance of visible scar defects, the size of scar defects or the thickness of the 
myometrium at the level of the isthmus uteri in nonpregnant women is not known. Although one would expect large scar defects to be associated with a higher risk of complications in future pregnancies (e.g. uterine rupture, uterine dehiscence, pathological implantation of placenta, scar pregnancies) than small scar defects or scars that appear intact at ultrasound examination, we do not know if this is the case ${ }^{(22)}$.

If thin myometrium in the isthmic area after Cesarean section in non-pregnant women proves to be predictive of complications, therefore measurement might become clinically important and provide the basis for studies on the clinical importance of Cesarean section scar defects and myometrial thinning after Cesarean section.

\section{Conclusion}

In conclusion, the present study found that ultrasound is more accurate than hysteroscopy in evaluating scar thickness and detection of scar defect.

\section{References}

1. Hsu CC, Shieh GR, Wu CS, Shen HC and Tang CH (2006): Risk adjustment for inter-hospital comparisons of cesarean section rates in Taipei municipal hospitals. Eur J Obstet Gynecol Reprod Biol., 127(2): 190-197.

2. Vikhareva O, Valentin L (2011): Clinical importance of appearance of Cesarean hysterotomy scar at transvaginal ultrasonongraphy in non pregnant women. Obstet Gynecol., 117:525-532.

3. Parè E, Quiñones JN and MaconesGA(2006): Vaginal birth after caesarean section versus elective repeat caesarean section: assessment of maternal downstream health outcomes.BJOG., 113 (1):7585 .

4. Asakura H, Nakai A, Ishikawa G, Suzuki S and Araki $T$ (2010): Prediction of uterine dehiscence by measuring lower uterine segment thickness prior to the onset of labor,evaluation by transvaginal ultrasonography. J Nippon Med Sch., 67 (5):352-356.

5. Tahseen $\mathbf{S}$, Griffith $\mathbf{S}$ (2010): Vaginal birth after two Cesarean sections(VBAC-2)- a systematic review with metanalysis of success rate and adverse outcome of VBAC-2 versus VBAC-1 and repeat (third) Cesarean sections. BJOG., 117: 5-19.
6. Landon MB, Hauth JC, Leveno KJ, Sponge CY, Varner MW (2004): Maternal and perinatal outcomes associated with a trial of labour after Cesarean delivery. N Eng J Med., 351:2581-2589.

7. Crowther CA, Dodd JM, Hiller JE, Haslam RR, Robinson JS et al.(2012) : Planned Vaginal Birth or Elective Repeated Cesarean: Patient Preference restricted, Cohort with Nested randomized Trial. PLOS Medicine., 9(3): e1001192.

8. Brill Y, Windrim R(2013): Vaginal birth after Cesarean section: review of antenatal predictors of success. J Obstet Gynecol Can., 25:275-280.

9. Jastrow N, Chaillet N, Roberge S, Morency AM, Lacasse Y, Bujold E (2010): Sonographic lower uterine segment thickness and risk of uterine scar defect: a systematic review. J Obstet Gynaecol Can., 32(4):321-327.

10. Birinyi L, Darago' $P$, Torok $P$, Csiszar $P$, Major T, Borsos A et al. (2004): Predictive value of hysteroscopic examination in intrauterine abnormalities. Eur J Obstet Gynecol Reprod Biol., 115(1):75-79.

11. Betran AP, Merialdi M and Lauer JA (2007): Rates of caesarean section: analysis of global, regional and national estimates. Paediatr Perinat Epidemiol., 21:98-113.

12. Hamilton BE, Minino AM, Martin JA, Kochanek KD, Strobino DM and Guyer B (2007): Annual summary of vital statistics: 2005. Pediatrics, 119: 345-360.

13. Monteagudo A, Carreno $C$ and TimorTritsch IE (2011): Saline infusion sonohysterography in non-pregnant women with previous cesarean delivery: the "niche" in the scar. J Ultrasound Med., 20:1105-1115.

\section{Jarvela IY, Sladkevicius P, Kelly S, Ojha K,} Campbell $S$ and Nargund $G$ (2012): Cesarean delivery scar. Ultrasound Obstet Gynecol., 19: 632-633.

15. Zimmer E, Bardin R, Tamir A, and Bronshtein M (2014): Sonographic imaging of cervical scars after Cesarean section. Ultrasound Obstet Gynecol., 23: 594-598. 
16. Osser $O$, Jokubkiene $L$, and Valentin $L$ (2009): High prevalence of defects in Cesarean section scars at transvaginal ultrasound examination. Ultrasound Obstet Gynecol., 34: 90-97.

17. Armstrong V, Hansen WF, Van Voorhis BJ and Syrop CH (2013): Detection of cesarean scars by transvaginal ultrasound. Obstet \&Gynecol., 121:61-65.

18. Menada Valenzano M, Lijoi D, Mistrangelo E, Costantini S and Ragni N (2014): Vaginal ultrasonographic and hysteronsonographic evaluation of the low transverse incision after caesarean section: correlation with gynaecological symptoms. Gynecol Obstet Invest., 61: 216-22.

19. Ofili-Yebovi D, Ben-Nagi J, Sawyer E, Yazbek J, Lee $C$, Gonzalez $J$ and Jurkovic D (2008): Deficient lower- segment Cesarean section scars: prevalence and risk factors. Ultrasound Obstet Gynecol., 31: 72-77.

20. Hanfy A and Abdel-Malek K (2011): Three dimensional ultrasound assessment of CS scar: A cross sectional study. KAJOG., 5258.

21. Vincent YTC, Oana CC and Birinder SA (2014): Sonographic evaluation of the lower uterine segment in patients with previous cesarean delivery. J Ultrasound Med., 23: 1441-1447.

22. Gotoh $\mathrm{H}$, Masuzaki $\mathrm{H}$, Yoshida A, Yoshimura S, Miyamura T and Ishimaru $T$ (2010): Predicting incomplete uterine rupture with Vaginal sonography during the late second trimester in women with prior cesarean. Obstet Gynecol., 95:596-600. 